\title{
Thyroid Cancer in Western Algeria: Histopathological and Epidemiological Study
}

\author{
A. Benouis ${ }^{1}$, Z. Bekkouche ${ }^{1}$, M. S. Merad ${ }^{2}$, L. Loudjedi ${ }^{3}$, H. Khelil ${ }^{3}$, N. Berber ${ }^{3}$ \\ ${ }^{1}$ Faculty of Nature and Life Sciences, Department of Biology, Laboratory of Biology of Development and Differentiation, \\ University of Oran, Oran, Algeria \\ ${ }^{2}$ Department of Endocrinology and Diabetology, Larribère Clinic U.H.C. of Oran, Oran, Algeria \\ ${ }^{3}$ Department of Nuclear Medicine U.H.C. of Tlemcen, Tlemcen, Algeria \\ Email:mms4819@yahoo.fr
}

How to cite this paper: Benouis, A., Bekkouche, Z., Merad, M.S., Loudjedi, L., Khelil, H. and Berber, N. (2017) Thyroid Cancer in Western Algeria: Histopathological and Epidemiological Study. Journal of Cancer Therapy, 8, 672-682.

https://doi.org/10.4236/jct.2017.87058

Received: May 14, 2017

Accepted: July 23, 2017

Published: July 26, 2017

Copyright (C) 2017 by authors and Scientific Research Publishing Inc. This work is licensed under the Creative Commons Attribution International License (CC BY 4.0).

http://creativecommons.org/licenses/by/4.0/

\begin{abstract}
Thyroid cancer is relatively rare, about $1 \%$ of all cancers combined. However, it accounts for $88 \%$ of all cancers of the endocrine organs. In recent years, the incidence of thyroid cancer has increased considerably compared to other types of endocrine cancers. The aim of our work is to study the epidemiological profile of thyroid cancer in the western part of Algeria and to determine the influence of sex, age and histological type. Patients and methods: Our study focuses on 1376 cases of thyroid cancer in patients attending the nuclear medicine department at the university hospital of Tlemcen over a period of 3 years, from 2013 to 2015. The average age of patients is estimated at 43. Each patient underwent an anatomo-histopathological examination of the surgical specimen. The data entry is done through the SPSS 20 statistical software. Results: The rates of the thyroid cancers listed during the three years of studies (2013-2014-2015) are 32.12\%, 34.44\% and 33.43\% respectively. Our study shows that the female sex is largely incriminated (94.75\%) compared to the male sex. The age group mostly affected was that ranging from 40 to 60 with $45.88 \%$. The anatomo-histopathological analysis revealed that the papillary carcinoma is the most frequent histological type with $85.47 \%$ followed by the vesicular carcinoma with $14 \%$, the medullary cancer MTC with $0.43 \%$, and finally the anaplastic carcinoma with $0.07 \%$. Conclusion: the epidemiological surveillance contributes to a better knowledge of thyroid carcinoma allowing a good patient management in Algeria. Early detection of small size cancers and the use of high-performing technologies will result in a decrease of the mortality rate associated to this type of cancer.
\end{abstract}

\section{Keywords}

Thyroid Cancer, Carcinoma, Epidemiological Profile, Western Algeria 


\section{Introduction}

The cancer of the thyroid is the most frequent endocrine cancer. It is increasing in all countries of the world, including Algeria. According to Pr. Hammouda, responsible for the Cancer Registry of Algiers (2006), the thyroid cancer holds the 5th place in order of frequency [1] while it occupied only the 15th row in 1980, [2]. Worldwide the highest rates are observed in the French and Italian registries, [2] [3] whereas the lowest ones are in the United Kingdom, the Netherlands, Denmark, Sweden and some registries in Germany [2]. The age adjusted international incidence rate has increased fivefold in men and tenfold in women [2]. In Algeria, the incidence standardized according to the world population is 7.7/100,000 in women and 2.9/100,000 in men [4].

Thyroid cancer can occur at any age although it is common after 30 and significantly more aggressive among the elderly. It is discovered in most of the cases when taking care of a thyroid nodule. Thyroid nodules are common, but only $5 \%$ are malignant. During the last twenty years, the development of diagnostic equipment (ultrasound and cytoponction) and changes in thyroid management practices have led to an increase in thyroid cancers, particularly papillary micro cancers. The main risk factors for thyroid cancer are: history of cervical irradiation in childhood; family and personal history of thyroid disease, hormonal factors, iodine intake and other dietary factors. Only the ionizing radiations received during childhood have an established responsibility for the occurrence of thyroid cancer. The thyroid cancers of Ukrainian and Belarusian children secondarily to the Chernobyl accident are a dramatic illustration of this [5].

The diagnosis is based on the anatomo-pathological examination of the surgical specimen, which remains difficult in some cases. The most frequent thyroid cancers (papillary and vesicular) are cured in $80 \%$ to $90 \%$ of cases, if the treatment is appropriate. Anaplastic and medullary cancers are rare and have a very unfavorable prognosis. Initial therapy for thyroid cancer is total or near total thyroidectomy. Ganglionic dissection is not systematic. Treatment with radioactive iodine is recommended in high-risk patients and requires a high thyroid stimulating hormone (TSH) to be effective. Subsequently, the patient must be placed on thyroid hormone replacement therapy for life. The prognostic factors of thyroid cancers are well known and allow correctly predicting the long term fate of the patients. There are the prognostic factors related to the characteristics of the patients like the sex or the age, those related to the initial tumor such as size and histological type and those related to the initial treatment [5].

The objective of our work is to determine the epidemiological and histopathological profile of thyroid cancer in the western Algerian region, which will make it possible to bring to the literature recent data on the progression of this type of cancer in our region.

\section{Patients and Method}

\subsection{Place and Period of Study}

The data of our study are listed from the register of the department of nuclear 
medicine of the U.H.C. of Tlemcen over a period of three years from 2013 till 2015. The department of nuclear medicine of Tlemcen is the reference department regarding the management of thyroid cancers in the West of Algeria.

\subsection{Population of Study}

Our work involves 1376 cases of differentiated thyroid (papillary and vesicular), medullary and undifferentiated (anaplastic) cancers diagnosed after anatomohistopathological examination of thyroid sample in patients sent to the U.H.C.T. The age of the patients is between 12 and 85 years with an average age estimated at 43 .

The patient management protocol is multidisciplinary and each case is submitted to the thyroid committee, which includes an endocrinologist, a nuclear physician, a surgeon and an anatomopathologist.

Patients were chosen from the data available in the service of nuclear medicine register, from the medical records of patients diagnosed with thyroid cancer. Inclusion criteria include all patients referred for thyroid cancer regardless of age, sex and histological type. The data are entered using anepidemiology specialized statistical software (SPSS 20).

\subsection{Data Analysis}

Cases of thyroid cancer have been described in men and women according to the age and year of diagnosis. The age at diagnosis was calculated in completed years by difference between the date of diagnosis and date of birth. The date of diagnosis corresponded to the date of the anatomopathological report when it was available or the date of the surgical stay when the date of the anatomical report was not filled. The histological type was studiedaccording to the information available in the medical and the histopathological reports.

\section{Results}

Our study concerning 1376 cases of thyroid cancers allowed to specify the number of cases for three years: 442 cases or $32.12 \%$ (2013), 474 cases or $34.44 \%$ (2014) and 460 cases or $33.43 \%$ (2015) [Figure 1]. The distribution by sex shows that women are widely incriminated compared to men. Over the three years, women represent an average of $94.75 \%$ of thyroid cancer versus $5.24 \%$ for men, [Figure 2]. The distribution by age shows a peak for the group of $40-60$ years (45.88\%), followed by the $60-80$ years (31.04\%) and the group of $20-40$ years (21.75\%), [Figure 3]. From the macroscopic point, the tumor presents a variable size, a variant consistency from soft to firm, well limited with occasional calcifications [Figure 4(a) and Figure 4(b)]. Histopathological analysis of tissue sample allows the distribution of malignant tumors of the thyroid in four main types, [Figure 5 and Figure 6]. The papillary carcinoma, with $85.47 \%$, is characterized by the presence of papilla. Its prognosis is favorable and its spread is lymphatic with nodal invasion, [Figure 7(a)]. The vesicular carcinoma, found in 


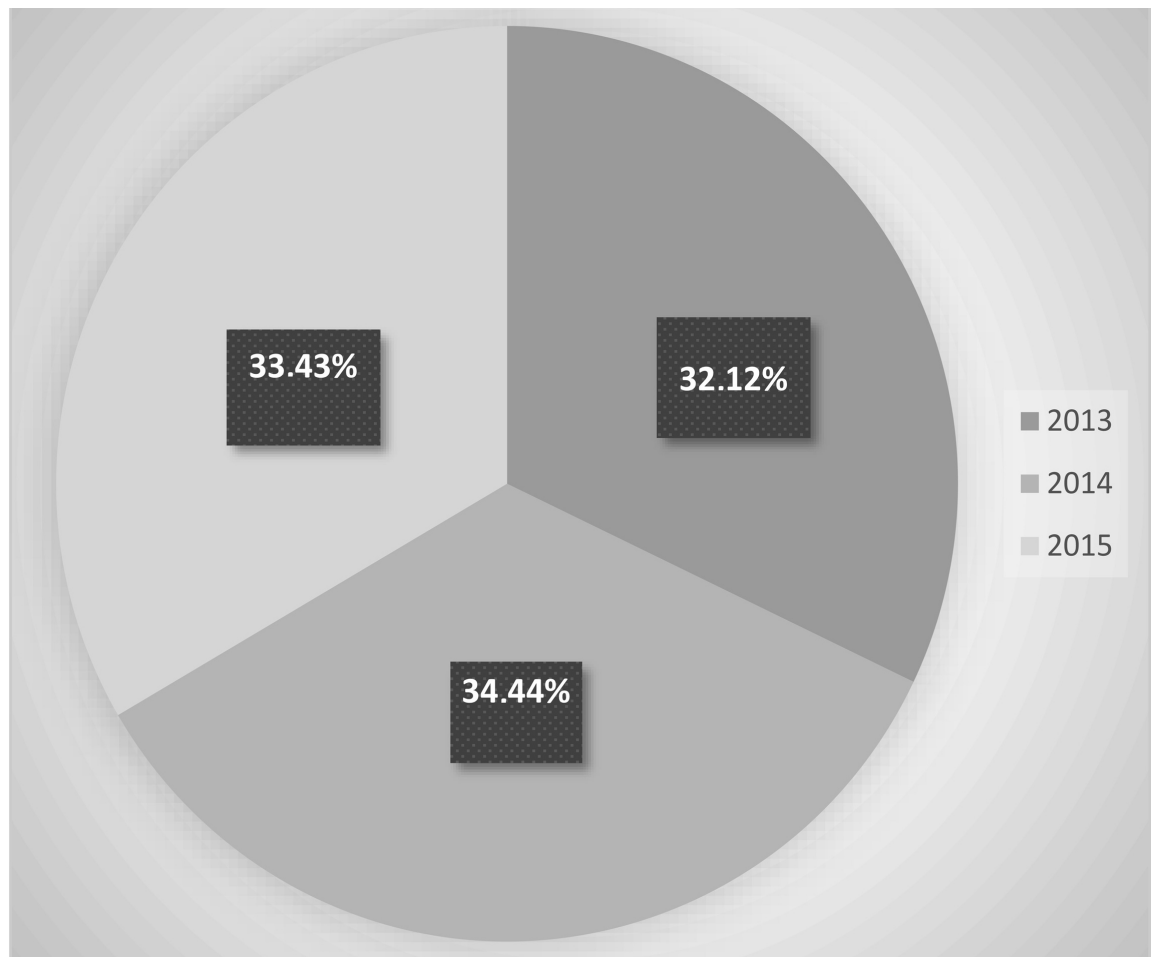

Figure 1. Global distribution of thyroid cancer per year.

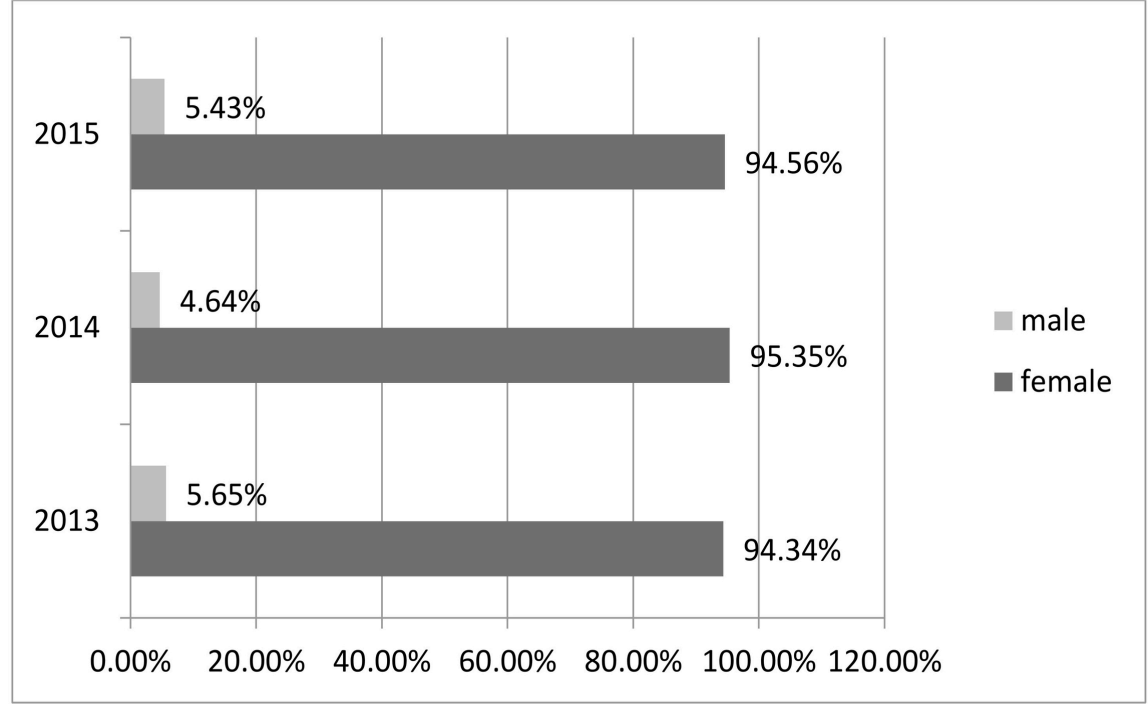

Figure 2. Distribution of thyroid cancer by sex of patients.

$14 \%$ of the cases, is often characterized by a polymorphic architecture. It is in relative decrease. Blood diffuses it and its prognosis is less favorable than that of the papillary carcinoma, [Figure $7(\mathrm{~b})$ ]. The medullary carcinoma is derived from C cells and is hereditary in $25 \%$ of the cases. It is a rare cancer with a good prognosis. It represents $0.43 \%$ of carcinoma registered in our study, [Figure $7(c)]$. The anaplastic carcinoma, found in $0.07 \%$ of the cases, is a rare cancer but of dreadful prognosis. It is extremely aggressive; it may be partially or totally undifferentiated, [Figure $7(\mathrm{~d})$ ]. 


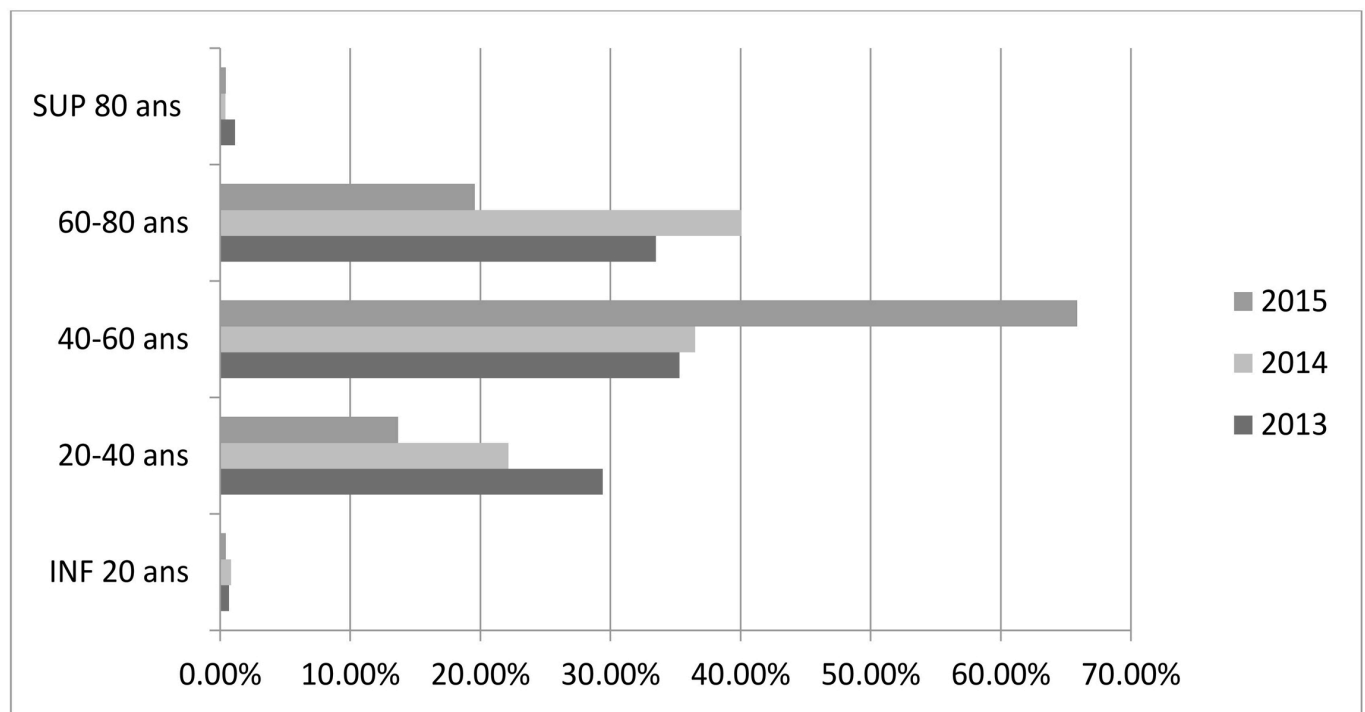

Figure 3. Distribution of thyroid cancer by age at diagnosis.

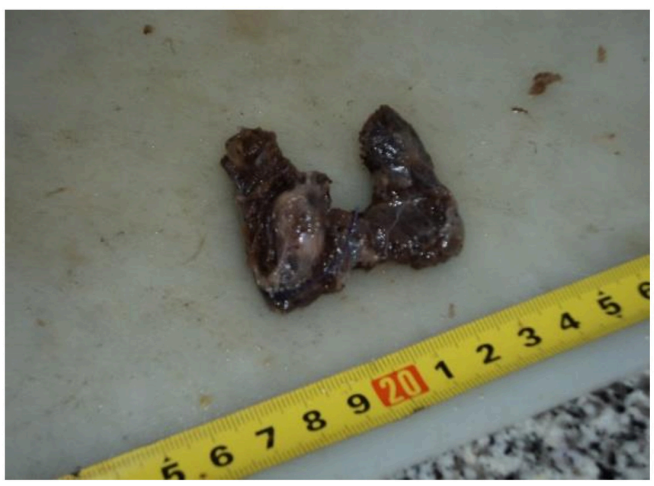

(a)

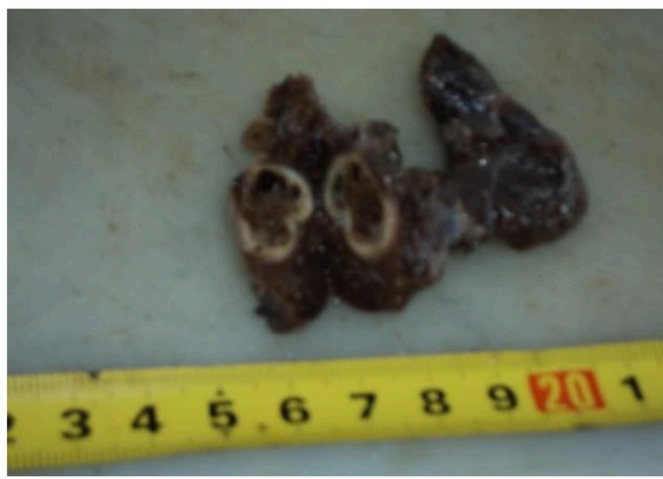

(b)

Figure 4. Macroscopic aspect of a thyroid gland after total thyroidectomy. (a) An entire surgical part oriented by wires. (b) Cut at suspect nodule level.

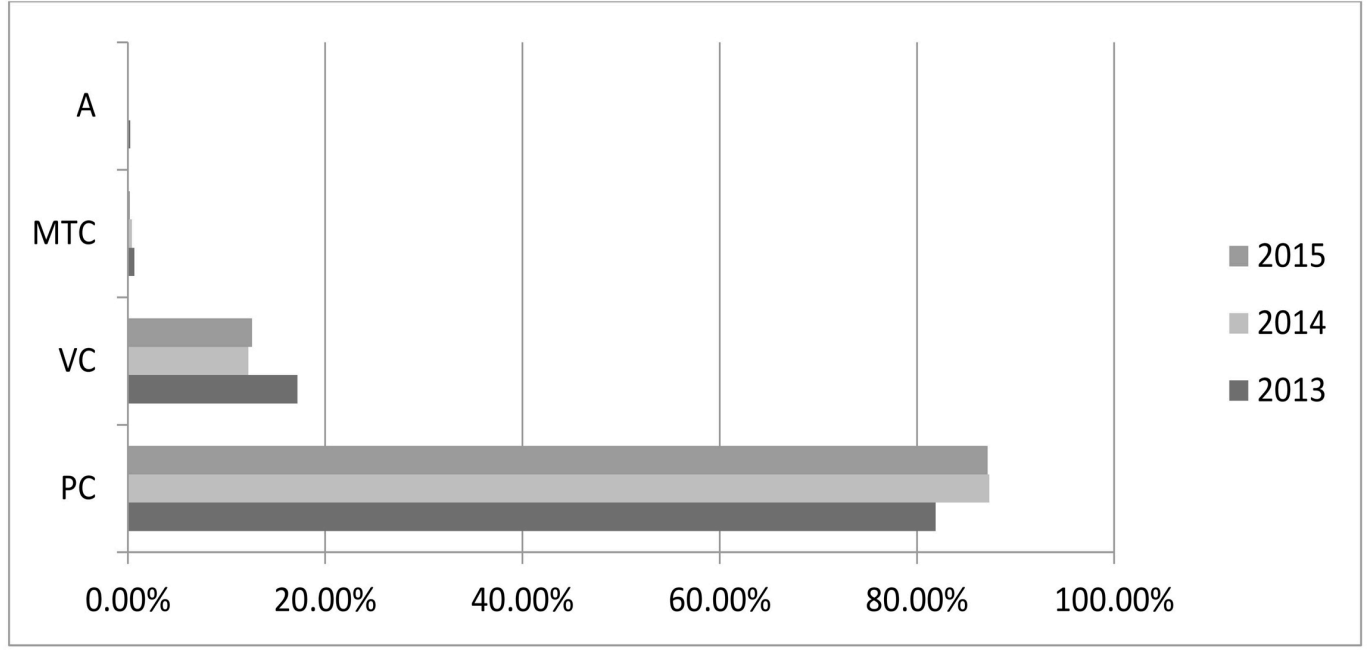

Figure 5. Global distribution of thyroid cancer by histological type. PC: papillary cancer, VC: vesicular cancer, MTC: medullary thyroid cancer, A: anaplastic cancer. 


\section{3}

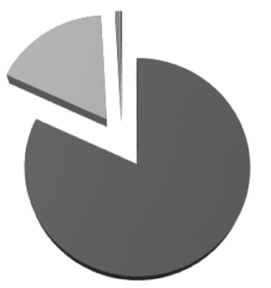

PC

VC

MTC

- A

\section{4}

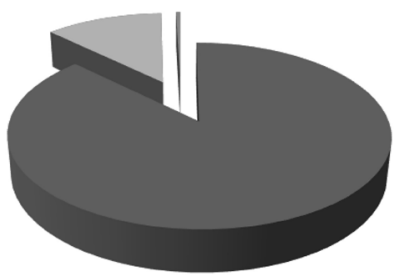

口C

VC

MTC

- A

\section{5}

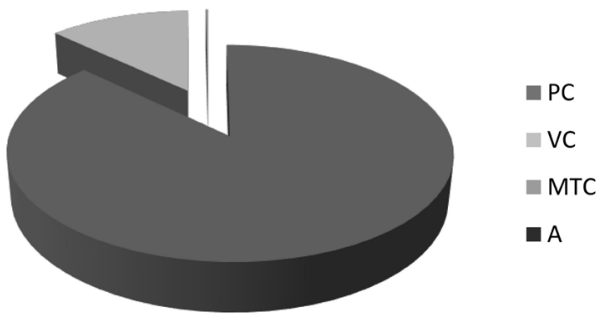

Figure 6. Distribution of thyroid cancer per year according to histological type. PC: papillary cancer, VC: vesicular cancer, MTC: medullary thyroid cancer, A: anaplastic cancer.

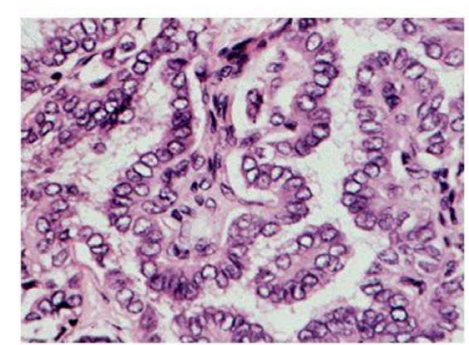

(a)

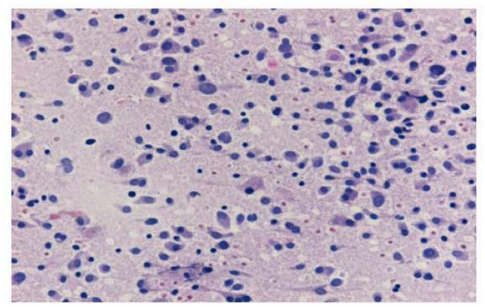

(c)

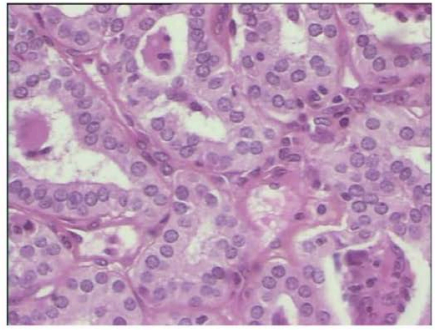

(b)

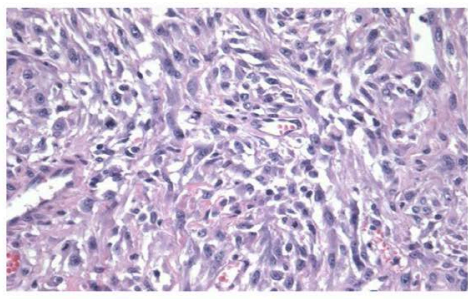

(d)

Figure 7. Microscopic observations: (a) Papillary cancer. (b) Vesicular cancer. (c) Medullary cancer. (d) Anaplastic cancer. 


\section{Discussion}

Our study allowed to list the thyroid cancers in western Algeria and to analyze the results compared to data from the literature.

\subsection{Distribution According to the Number of Thyroid Cancers Cases}

In Algeria: the Larbi study (2008) recorded 1240 cases from 1998 to 2006, [4]. In another work of Boumansour et al., from February 2011 to December 2012 at the University Hospital Establishment of Oran (U.H.E.O), 32 cases were registered, [6]. In Morocco, Benrais et al. recorded 3144 cases of differentiated thyroid cancer collected over a 20-year period from 1987 to 2007 [7]. In Mali, Keita registered 58 cases among 915 thyroid samples collected over a ten-year period from January 1996 to December 2005, [8]. In Madagascar (2010), Rakotoarisoa et al. recorded 40 cases over a 13-month period among 179 thyroid sample, [9]. In France, the number of new cases was estimated at 2183 in men and 6820 in women in 2010, [3]. In the Reunion Island (1997), Montury et al. recorded 3.2\% of cases, [10]. In Corsica: fauconnier listed 201 cases between 1985 and 2006, [11]. Similarly, Pascal and Lasalle recorded 342 cases between 1998 and 2006, [12]. In France, Corsica is one of the regions, most affected by the fallout from the Chernobyl accident. In another study of Barret in the U.H.C. of Nantes from January 2001 to December 2008, 199 cases were recorded, [13]. Our study reports 1376 cases over three years, which is considerable considering that our analysis focuses only on the Algerian West.

The increase observed in most countries, in both men and women, is mainly due to the increase in papillary and small cancers. It is the evolution in the differentiated cancers medical management of the thyroid that would be the cause, with the early detection through the association of cervical ultrasound and fine needle cytopuncture. Studies show that this increase is largely due to the diagnosis of small early-stage cancers, most of which do not evolve toward clinical expression. Clinical practices have changed a lot in recent years. The thyroid gland is better monitored, especially when examinations are performed in the cervical region for other indications, and the technologies used are increasingly performing. However, the evolution of diagnostic practices alone cannot explain all the increase observed. Although other risk factors are suspected, the one with the most established causality is exposure to ionizing radiation during childhood. The growing exposure to ionizing radiation from medical and dental imaging examinations is a topic to be addressed from a public health perspective, [14]. Moreover, although the Chernobyl accident happened 30 years ago, the idea that its fallout would be partly responsible for the increase of this type of cancer in France, in this case very remote from highly contaminated regions (Belarus, Ukraine and Russia), remains firmly anchored in many minds [15].

\subsection{Distribution According to the Sex of Patients}

In the study done at U.H.C. of Tlemcen (Algeria), Bouklikha and Djamel rec- 
orded $88 \%$ of cancer cases in women compared to $12 \%$ in men, [16]. In Morocco, Benrais et al. showed that the ratio is 3.5 women for 1 man, [7]. In Mali in 2007, Keita notes the feminine predominance with 79.3\%, [8]. In Madagascar in 2010, Rakotoarisoa et al. noted the feminine predominance with $82 \%$ [9]. In France: according to the study by Montury et al., women represent $82 \%$ and men $18 \%$, [10]. In Corsica, fauconnier's works show that $71 \%$ of thyroid cancer is found in women, [11] and those of Pascal and Lasalle showed that the cases are 2.3 times more in women than in men, [12]. In Nantes, Barret's work in 2001- 2008 show that women represent $79.90 \%$ and men $20.10 \%$ [13]. In the case of the thyroid cancer, we observe a near female predominance (94\%). Our results are like most of the literature which find a high proportion of females. The origin of this sexual inequality is due to hormonal factors specific to women, as well as pregnancies that favor the formation of goiters and thyroid nodules.

\subsection{Distribution According to Age of Patients at the Time of Diagnosis}

In Algeria: according to the work of Larbi (2008), the modal age is around sixty, [4]. The study of Boumansour et al. at the U.H.E. of Oran shows that the most affected age group is the 30 - 40 years, [6]. Moreover, Bouklikha and Djamel in U.H.C. of Tlemcen (2009-2013) registered the highest rate in the 30 - 60 years with a peak between 41 - 50 ans (47 cases), [16]. In Morocco, Benrais et al. show that the age at diagnosis is 42.5 years for the papillary carcinoma and 48 years old for the vesicullar carcinoma, [7]. In Mali, Keita records $24.1 \%$ for the $40-49$ years and $20.7 \%$ for the 50 - 59 years. The average age is 44.5 years with extremes of ranging from 13 to 75 years, [8]. In Madagascar, Rakotoarisoa et al. note that the average age is 43.9 years at the time of anatomo-pathological diagnosis, [9]. In France: on the Reunion Island, Montury et al. record a high rate between 40 60 with a peak between 50 - 60 years, [10]. In Corsica, Fauconnier reports that the cases cited predominate between 30 and 70 years, [11]. Similarly, Pascal and Lasalle show that the maximum number of thyroid cancers has occurred in people aged between 50 and 59 years, [12]. In U.H.C. of Nantes, Barret shows that the average age of the 199 patients of the studied population is 45.5 years. Indeed, the differentiated cancer of the thyroid affects the young subject with an average age of 40 years, [13]. Age is a determining factor in thyroid cancer; the peak is between 40 - 60 years in our study. These data are consistent with literature studies.

\subsection{Distribution According to Histological Type}

In Algeria: according to the work of Boumansour et al., the papillary carcinoma predominates with 62.5\%, [6]. In another study by Dr. Hadj Arab (2008) of Endocrinology department of CPMC a series of 530 patients who reported a predominance of the papillary carcinoma with $60 \%$ of cases versus $40 \%$ of vesicular carcinoma, [4]. In the work of Benrais et al. in Morocco: $66 \%$ of papillary carci- 
noma is recorded against $22 \%$ of well differentiated vesicular carcinoma and $12 \%$ undifferentiated vesicular carcinoma, [7]. In France: the study of Montury et al. recorded $28 \%$ of papillary carcinoma, $13 \%$ of vesicular carcinoma and one case of a plastic cancer, [10]. In Corsica, Pascal and Lasalle registered $79.5 \%$ of papillary carcinoma, $14.1 \%$ of vesicular carcinoma, $5.6 \%$ of medullary cancer and $0.9 \%$ of other histological types, [12]. In U.H.C. of Nantes, Barret found 93.47\% of papillary carcinoma and 6.53\% vesicular carcinoma, [13]. According to Rogel et al. the papillaryhistologic type is most frequently found in literature cohorts and accounts forabout $80 \%$ of the differentiated cancers of the thyroid, [14].

According to Pascal and Lasalle, the histological classification of thyroid cancer is based on the degree of differentiation of cancer cells and their rate of growth and distinguishes four main histological types:

- Papillary (60\% - 70\% of cases) of good prognosis and encountered in rather young subjects;

- Vesicular or follicular ( $15 \%$ to $20 \%$ of cases) with a slightly worse prognosis;

- Anaplastic or undifferentiated (less than 5\% of cases) with poor prognosis;

- Medullary which is a particular problem (tumor derived from the thyroid cell C) and of which $25 \%$ of the cases are family forms [12].

Histologically, two classifications of thyroid tumors are most commonly used by pathologists: the World Health Organization (WHO) classification in its latest edition of 1988 and the Atlas of the US Army or AFIP (1991 Edition) [5].

Comparative analysis with data from the literature allowed us to classify the different histological types of thyroid cancer according to the WHO and AFIP classifications and to show that malignant epithelial tumors (papillary and vesicular carcinoma) dominate with predominance of papillary carcinoma. Medullary cancer developed at the expense of "C" cells is much less common and undifferentiated anaplastic cancer remains very rare. Our results agree with the majority of the literature.

\section{Conclusion}

Thyroid cancer usually develops in the form of a nodule situated within the thyroid gland be it in a normalor increasedsized (goiter). Our analysis shows that the rate of thyroid cancers is high and stable during the three years of study. Women are more exposed at the risk of developing this cancer with an average age estimated at 43 ans. Histologically, the papillary carcinoma is the most frequent with a good prognosis. The vesicular carcinoma is less frequent and both of medullary and anaplastic cancers remain very rare. Our retrospective descriptive study is limited by the fact that the data collection is done in a single center which is considered as the center of reference for the management of thyroid cancer in West Algeria (the nuclear medicine department of Tlemcen) which can be considered as a selection ticket. Nevertheless, our results are glo- 
bally like those brought back by the literature and show that the thyroid cancers are progressing in the Algerian West. This analysis stresses the necessity of an early management that will help reduce the mortality rate due to this type of cancer.

\section{Conflict of Interests}

The authors of this article declare to have no conflict of interests.

\section{References}

[1] Hammouda, D., Aoun, M., Bouzerar, K., et al. (2006) Registre des tumeurs d'Alger.

[2] Lalmi, F., Sadoul, J.L. and et Rohmer, V. (2015) Les cancers de la thyroide: De l'épidémiologie à la biologie moléculaire. Annale d' Endocrinologie, 76, 19-28. https://doi.org/10.1016/S0003-4266(16)30004-X

[3] Klotz, L.L. and et Grosclaude, P. (2011) Épidémiologie des cancers thyrö̈diens dans le monde. Annales d Endocrinologie, 72, 136-148. https://doi.org/10.1016/j.ando.2011.03.025

[4] Abid, L. (2008) Le cancer de la thyroïde en Algérie. Guide de la santé en Algérie: Actualité pathologie.

[5] Leenhardt, L., Ménégaux, F., Franc, B., et al. (2005) Cancers de la thyroide. Endocrinologie-Nutrition EMC, 10-008-A-50, 1-27.

[6] Boumansour, N., Beldjilali, H., Agag, F., et al. (2014) Profil épidémiologique des cancers thyroïdiens à l'Ouest algérien. Service d'épidémiologie et de médecine préventive de l'Établissement hospitalier et universitaire d'Oran, Algérie. Revue Epidémiologique de Santé Publique, 62, 214.

[7] Ben Rais, A., Ghfir, I., Missoum, F., et al. (2008) Etude épidémiologiquedu cancer différencié de la thyroide (médullaire exclu) au Maroc. Médecine nucléaire, 32, 580 584. https://doi.org/10.1016/j.mednuc.2008.09.002

[8] Adama, K. (2007) Le cancer de la thyroide au Mali: Aspects épidémiologiques et anatomocliniques. Thèse de médecine.

[9] Rakotoarisoa, A.H.N., Ralamboson, S.A., Rokotoarivelo, R.A., et al. (2010) Les cancers de la thyroide à Madagascar. Bulletin de la Société pathologique exotique, 103, 233-237. https://doi.org/10.1007/s13149-010-0063-y

[10] Montury, S., de Clermont, H. and et Gatina, J.H. (1997) Prévalence des cancers thyroïdiens à la Réunion à partir des données scintigraphiques. Communication, 9 , 4 .

[11] Fauconnier, S. (2006) Etude de 201 cas de cancers de la thyroïde en Corse entre 1985 et 2006. Thèse de doctorat en médecine, université Rene Descartes Paris 5.

[12] Pascal, L. and Lasalle, J.L. (2012) Estimation de l'incidence du cancer de la thyroïde en Corse (1998-2006). Saint-Maurice: Institut de veille sanitaire, 1-27.

[13] Barret, A. (2013) Etude du dosage de la thyroglobuline stimulée dans le suivi de patients traités pour un cancer différencié de la thyroïde au CHU de Nantes: Comparaison des valeurs de dosage après stimulation par TSH endogène ou Thyrogen ${ }^{\circledast}$ et choix de la valeur seuil. Thèse doctorat en pharmacie.

[14] Rogel, A., Bernier, M.O., Motreff, Y., et al. (2016) Epidémiologie du cancer de la thyroïde 30 ans après l'accident de tchernobyl: Fréquence, facteurs de risque et impact des pratiques diagnostiques. Bulletin épidémiologique hebdomadaire $B E H$, 11-12, 200. 
[15] Bourdillon, F. and et Repussard, J. (2016) Cancer de la thyroïde et accident nucléaire: Où en sommes-nous 30 ans après tchernobyl et 5 ans après fukushima? Bulletin épidémiologique hebdomadaire BEH, 11-12, 198.

[16] Bouklikha, C. and et Sefiane, D. (2014) Cancer de la thyroide. Thèse de doctorat en médecine, université de Tlemcen (Algérie).

Submit or recommend next manuscript to SCIRP and we will provide best service for you:

Accepting pre-submission inquiries through Email, Facebook, LinkedIn, Twitter, etc. A wide selection of journals (inclusive of 9 subjects, more than 200 journals)

Providing 24-hour high-quality service

User-friendly online submission system

Fair and swift peer-review system

Efficient typesetting and proofreading procedure

Display of the result of downloads and visits, as well as the number of cited articles Maximum dissemination of your research work

Submit your manuscript at: http://papersubmission.scirp.org/

Or contact jct@scirp.org 